\title{
QUADCOPTER OBSTACLE AVOIDANCE DENGAN SENSOR INFRAMERAH UNTUK PEMANTAUAN BENCANA ALAM MELALUI UDARA
}

\author{
I Gede Andika1), Christina Purnama Yanti²), Made Cardewa ${ }^{3)}$ \\ 1 Ilmu Komputer, Universitas Pendidikan Ganesha \\ email: gdandika@stiki-indonesia.ac.id \\ 2 Ilmu Komputer, Universitas Pendidikan Ganesha \\ email: christinapurnamayanti@gmail.com \\ 3 Sistem Komputer, STMIK STIKOM Indonesia \\ email: madecardewa@gmail.com
}

\begin{abstract}
Abstrak
Pemantauan lokasi bencana alam melalui udara dengan helikopter sulit dilakukan karena memerlukan banyak ruang untuk mendarat dan rentan dengan benturan jika diterbangkan pada ketinggian yang rendah. Penelitian ini bertujuan untuk merancang dan membangun quadcopter obstacle avoidance sebagai solusi alternatif pengganti helikopter. Quadcopter yang dibuat dilengkapi dengan sensor inframerah yang berfungsi untuk mendeteksi adanya halangan. Keluaran dari sensor inframerah berupa LED (Light Emitting Diode) yang menunjukkan sensor bagian mana yang mendeteksi halangan, serta buzzer sebagai keluaran suara. Quadcopter obstacle avoidance ini diuji di dalam dan luar ruangan dengan digantung pada tiang horizontal, kemudian throttle dinaikkan sehingga motor berputar, kemudian sebuah halangan didekatkan dengan quadcopter. Hasil yang diperoleh dari penelitian ini adalah sebuah prototype quadcopter obstacle avoidance dengan sensor inframerah yang mampu mendeteksi halangan dari $20 \mathrm{~cm}$ hingga $80 \mathrm{~cm}$ serta mampu memberi respon berupa gerakan feedback dengan tingkat akurasi pada luar ruangan yaitu $61.25 \%$, dan tingkat akurasi di dalam ruangan yaitu $100 \%$.
\end{abstract}

Kata kunci: quadcopter, bencana alam, obstacle avoidance, inframerah.

\begin{abstract}
Monitoring natural disasters location through the air by helicopter is difficult because it requires a lot of space to land and vulnerable with a collision if flown at low altitude. This research aims to design and build an obstacle avoidance Quadcopter as an alternative solution replacement of helicopter. Quadcopter is equipped with infrared sensors to detect any obstacle. The output of infrared sensors in the form of LEDS that indicate which parts of the sensor detects an obstacle, as well as the buzzer output sound. Quadcopter obstacle avoidance was tested inside and out of the room by hanging on a pole horizontally, then throttle is raised so that the motor is spinning, then an obstacle brought closer to Quadcopter. The results obtained from this research is a prototype Quadcopter obstacle avoidance with infrared sensors capable of detecting an obstacle from $20 \mathrm{~cm}$ to $80 \mathrm{~cm}$ and is able to give a response in the form of motion feedback with the level of accuracy at the outdoor is $61.25 \%$ accuracy rate, and indoor is $100 \%$.
\end{abstract}

Keywords : quadcopter, natural disaster, obstacle avoidance, infrared

\section{PENDAHULUAN}

Melihat posisi geografis Indonesia yang terletak di ujung pergerakan tiga lempeng dunia, yaitu Eurasia, IndoAustralia dan Pasifik, menjadikan Indonesia sebagai negara yang rawan terhadap bencana. Bencana alam merupakan suatu peristiwa alam yang berdampak pada manusia dan bumi itu sendiri. Jenis bencana alam yang sering terjadi di Indonesia adalah jenis bencana alam meteorologi yang berhubungan dengan iklim seperti banjir, kekeringan, dan bencana alam yang terjadi pada permukaan bumi (geologi) seperti gempa bumi, gunung meletus, tanah longsor. Dampak yang ditimbulkan oleh bencana tersebut sangat merugikan bagi masyarakat sekitarnya. Selain kerugian materi, seringkali proses 
evakuasi atau pencarian korban juga memerlukan waktu yang lama karena keadaan lokasi bencana yang susah diakses.

Untuk mencegah terjadinya kerugian maka diperlukan upaya seperti pencegahan, mitigasi, kesiapan dan peringatan dini. Namun saat bencana sudah terjadi, penanggulangan bencana tanggap darurat seperti evakuasi korban harus segera dilaksanakan. Dalam prosesnya, evakuasi dan pemantauan lokasi bencana dapat dilakukan melalui jalur darat dan udara. Melalui jalur darat, biasanya menggunakan alat berat serta bantuan dari sukarelawan. Namun resiko yang dihadapi cukup banyak seperti jalur yang susah diakses, dan kemungkinan bertambahnya korban dari tim evakuasi. Sedangkan melalui jalur udara, biasanya menggunakan bantuan helikopter untuk menyisir lokasi bencana. Namun helikopter membutuhkan landasan khusus sebagai tempat mendarat, dan tidak bisa melakukan penyisiran secara maksimal karena ukurannya yang relatif besar dan rentan terhadap benturan. Sehingga diperlukan suatu alat pemantau yang memiliki kemampuan seperti helicopter, namun bahkan mampu terbang lebih rendah sehingga evakuasi dapat dilakukan dengan lebih efisien. Salah satu alat pemantau yang bisa digunakan adalah quadcopter.

Quadcopter adalah sebuah sistem robot terbang tanpa awak yang memiliki empat buah motor sebagai penggeraknya, dan dapat dikendalikan dari jarak jauh sehingga dapat dimanfaatkan untuk melakukan pemantauan dari jarak jauh tanpa memasuki lokasi bencana. Namun dalam proses pemantauan, perlu diperhatikan lingkungan sekitar bencana. Pohon-pohon dan bangunan tinggi merupakan halangan bagi quadcopter. Quadcopter yang dirancang nantinya diharapkan mampu mendeteksi halangan dan menghindari halangan tersebut dengan bantuan sensor inframerah. Pada saat quadcopter mendeteksi adanya halangan pada jarak yang telah ditentukan, maka quadcopter akan bereaksi dengan bergerak berlawanan arah dengan halangan, sehingga sistem akan selalu menyesuaikan jaraknya dengan halangan.

\section{TINJAUAN PUSTAKA}

\section{Quadcopter}

Salah satu jenis UAV (Unmanned Aerial Vehicle) yang termasuk kedalam kategori micro dan banyak digunakan adalah quadcopter. UAV jenis ini memiliki ciri khusus yaitu empat buah baling-baling motor yang digunakan sebagai penggeraknya. Secara umum sebuah quadcopter terdiri dari komponen piranti keras dan piranti lunak. Pada komponen piranti keras, terdiri dari sistem mekanik dan elektronik. Pada sistem elektronik seperti sensor, motor driver, dan mikrokontroler. Komponen-komponen tersebut diletakkan dibagian tengah membentuk lingkaran atau persegi, serta empat baling-baling di sekitarnya pada posisi yang bersilangan. Struktur penyusun persilangan tersebut cukup tipis dan ringan, tetapi juga cukup kuat untuk menghubungkan struktur keempat balingbaling. Setiap baling-baling terhubung ke motor melalui reduction gear (roda gigi yang mengurangi kecepatan putaran masukan pada keluarannya). Sumbu rotasi setiap baling-balingnya selalu kaku, dimana hanya kecepatan baling-baling yang bisa divariasikan. Kecepatan baling-baling ini berperan penting terhadap pergerakan dari quadcopter.

\section{Prinsip Kerja Quadcopter}

Quadcopter memiliki dua pasang baling-baling, dimana pasangan tersebut bergerak berlawanan arah dengan pasangan lainnya. Baling-baling a dan $c$ bergerak searah jarum jam, sedangkan baling-baling $b$ dan $d$ bergerak berlawanan. Konfigurasi arah berlawanan dari balingbaling ini dapat menggantikan kebutuhan untuk memiliki baling-baling diekor sebagaimana yang dimiliki helicopter standar yang digunakan untuk mengatur arah pergerakan. Quadcopter memiliki ketentuan tersendiri terhadap variasi kecepatan perputaran setiap balingbalingnya untuk dapat terbang melayang di udara yang dikenal dengan sebutan hover. Quadcopter perlu menggerakkan keempat baling-balingnya dengan kecepatan yang sama. Setiap pasangan baling-baling memiliki arah gaya dorong yang memiliki 
fungsi berbeda, satu pasang sebagai pendorong (pusher) dan satu pasang sebagai penarik (puller).

\section{Penelitian Sebelumnya}

Salah satu penelitian sebelumnya terkait quadcopter dilakukan oleh I.B. Alit Swamardika, dkk (2014) dengan judul Rancang Bangun Quadcopter Robot Sebagai Alat Pemantau Jarak Jauh Kawasan Lingkungan Bencana. Swamardika, dkk merancang dan membangun quadcopter yang dikendalikan oleh remote control (RC) dan mampu terbang pada ketinggian 10 sampai 15 meter dari permukaan tanah. Quadcopter karya Swamardika, dkk sepenuhnya dikendalikan melalui RC. Penelitian ini menawarkan pengembangan alternatif quadcopter yang mampu menghindari halangan berupa gerakan feedback ke arah berlawanan dari arah halangan terdeteksi.

\section{Mikrokontroler}

Mikrokontroler adalah sebuah sistem komputer fungsional dalam sebuah chip. Di dalamnya terkandung sebuah inti prosesor, memori (sejumlah kecil RAM, memori program, atau keduanya), dan perlengkapan input output. Dengan kata lain, mikrokontroler adalah suatu alat elektronika digital yang mempunyai masukan dan keluaran serta kendali dengan program yang bisa ditulis dan dihapus dengan cara khusus. Cara kerja mikrokontroler sebenarnya membaca dan menulis data. Mikrokonktroler digunakan dalam produk dan alat yang dikendalikan secara otomatis, seperti sistem kontrol mesin, remote kontrol, mesin kantor, peralatan rumah tangga, alat berat, dan mainan. Dengan mengurangi ukuran, biaya, dan konsumsi tenaga dibandingkan dengan mendesain menggunakan mikroprosesor memori, dan alat input output yang terpisah, kehadiran mikrokontroler membuat kontrol elektrik untuk berbagai proses menjadi lebih ekonomis.

\section{Sensor Inframerah Sharp GP2YOA21}

Sensor ini termasuk pada sensor jarak kategori optic. Pada dasarnya, sensor ini sama seperti sensor InfraRed (IR) konvensional. GP2YOA21 memiliki bagian transmitterlemitter dan receiver (detector). Bagian transmitter akan memancarkan sinyal IR, sedangkan pantulan dari IR (apabila mengenai sebuah objek) akan ditangkap oleh bagian detector yang terdiri dari lensa fokus dan sebuah linier $C C D$ array. Linier CCD array terdiri atas sederetan elemen peka cahaya yang disebut piksel (picture element). Sensor inframerah digunakan dalam penelitian ini karena harganya yang terjangkau, mudah didapatkan serta banyaknya referensi yang tersedia. Sensor inframerah digunakan sebagai awal prototype sebelum menggunakan sensor yang mampu melakukan pendeteksian objek lainnya.

\section{METODE PENELITIAN}

Adapun alur yang digunakan pada penelitian ini yaitu diawali dengan pengumpulan data. Pengumpulan data merupakan langkah yang sangat penting dalam metode ilmiah, karena data digunakan untuk menguji hipotesa yang telah dirumuskan. Dalam penelitian ini, terdapat dua jenis data yang akan dikumpulkan yaitu data primer dan sekunder.

Pada mengumpulan data primer, penulis menggunakan teknik wawancara. Penulis melakukan wawancara terhadap Bapak Nyoman Swanjaya, S.E., M.Si selaku Kepala Seksi Peringatan Dini, Data, dan Pelayanan Informasi Kebencanaan di UPT Pusat Pengendalian Operasi Penanggulangan Bencana (PUSDALOPS) Badan Penanggulangan Bencana Daerah (BPBD) Provinsi Bali. Dari wawancara tersebut, didapatkan data dan informasi mengenai bagaimana melakukan pencegahan sebelum bencana terjadi dan telah melakukan berbagai sosialisasi dengan masyarakat yang berada di daerah rawan bencana. Selain itu juga diperoleh informasi bagaimana penanganan pada saat bencana terjadi, serta menjelaskan apa saja yang dibutuhkan di lokasi bencana setelah bencana terjadi, dan bagaimana kendala yang dihadapi.

Data sekunder diperoleh melalui dua metode, yaitu metode kepustakaan dan metode dokumentasi. Teknik studi pustaka 
dilakukan dengan membaca buku dan literatur teori mengenai perancangan quadcopter mulai dari proses perancangan hingga dihasilkan quadcopter yang mampu terbang yang dijadikan acuan dalam perancangan quadcopter dengan kamera sebagai sarana pemantauan bencana alam melalui udara. Sedangkan dengan metode dokumentasi dengan cara mengambil langsung data dan informasi pada Badan Penanggulangan Bencana Daerah Provinsi Bali.

Setelah dilakukan pengumpulan data, selanjutnya dilakukan analisis data dan kebutuhan sistem. Dari hasil analisis data, masih adanya peningkatan jumlah korban yang membuktikan bahwa pemantauan untuk menanggulangi bencana masih kurang. Alat berat yang digunakan saat terjadi bencana alam seperti tanah longsor masih berasal dari dinas PU. Sehingga pada saat terjadi bencana, BPBD harus melakukan koordinasi terlebih dahulu. Keadaan ini memiliki kelemahan yaitu BPBD tidak bisa bergerak cepat saat bencana terjadi. Selain itu, saat menggunakan helikopter untuk menyusuri lokasi bencana ditemukan kendala seperti tidak ada tempat untuk melakukan pendaratan pada lokasi bencana. Dapat disimpulkan bahwa untuk menangani bencana alam tidaklah cukup hanya dengan alat berat dan helicopter saja, akan tetapi harus ada alternatif yang dapat dijadikan pilihan untuk melakukan pemantauan dan evakuasi pada saat terjadinya bencana. Berdasarkan hal tersebut, maka perlu untuk membuat sebuah sistem quadcopter sebagai wahana untuk melakukan pemantauan dan evakuasi pada saat terjadi bencana alam. Adapun kemampuan dari sistem yang diusulkan adalah sebagai berikut:

1. Sistem yang dirancang mampu melakukan pemantauan pada lokasi bencana.

2. Sistem tidak membutuhkan tempat yang luas untuk mendarat.

3. Sistem mampu bertahan pada lokasi bencana dengan menghindari halangan di sekitarnya.

\section{Kebutuhan Sistem}

Dari analisa sistem di atas, maka dapat ditentukan kebutuhan sistem yang akan dibuat yaitu:

1. Jenis kerangka quadcopter yang digunakan adalah jenis $\mathrm{X}$ agar kerangka tidak menghalangi hasil dari kamera yang digunakan untuk mengambil gambar.

2. Menggunakan baterai lipo $2200 \mathrm{mAh} 11,1$ volt yang mampu bertahan 10-15 menit.

3. Menggunakan sensor inframerah untuk mendeteksi halangan.

4. Menggunakan

mikrokontroler ATMega328 sebagai pusat pemrosesan data sehingga mampu menghindari halangan.

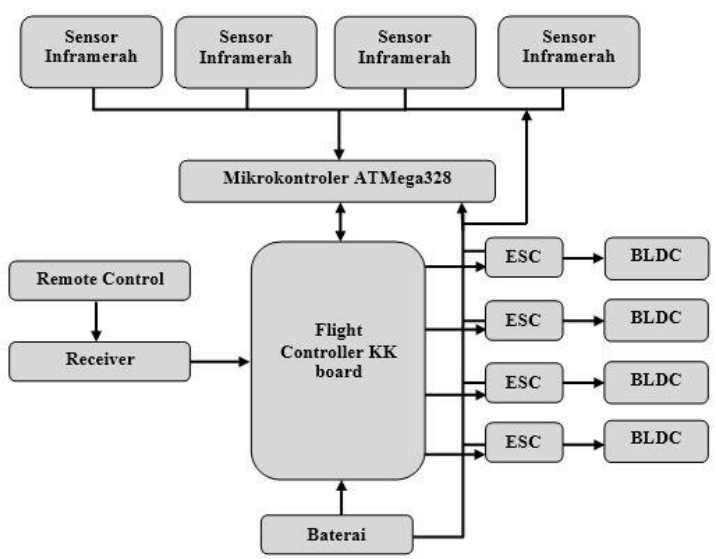

Gambar 1. Blok Diagram Rancangan Sistem

Keseluruhan sistem ini akan ditenagai oleh baterai lipo dimana fungsinya sebagai penyimpan energi dan kemudian mengeluarkannya dalam bentuk tegangan dan disalurkan ke beberapa komponen seperti mikrokontroler, flight controller, dan Electronics Speed Controller (ESC).

Selain dikendalikan secara manual oleh user, sistem juga dapat bergerak otomatis dengan bantuan sensor inframerah yang berfungsi untuk mendeteksi halangan di sekitar sistem. Sensor tersebut nantinya akan ditempatkan pada bagian depan, belakang, bagian kiri, dan kanan sistem. Saat mendeteksi adanya halangan, maka sensor akan mengirimkan input ke mikrokontroler ATMega328 dan hasilnya akan dikirimkan ke flight controller sehingga dapat menentukan arah 
pergerakan dengan bantuan ESC yang berfungsi sebagai pengendali motor.

\section{Perancangan Perangkat Keras}

Perangkat keras quadcopter terdiri dari beberapa bagian, seperti terlihat pada Gambar 2.

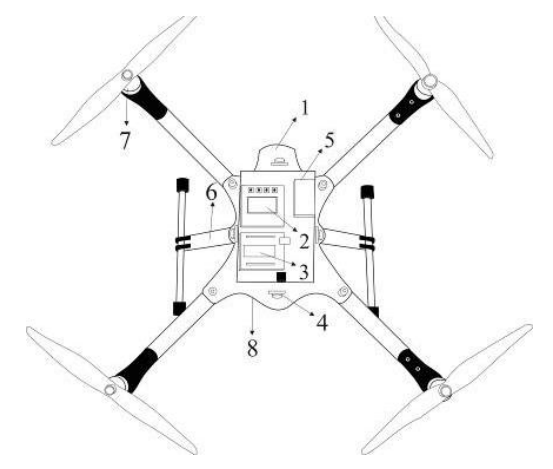

Gambar 2. Perancangan Perangkat Keras Keseluruhan.

1. Kerangka (Frame)

Quadcopter yang dirancang pada penelitian ini memiliki bentuk kerangka jenis $X$ quadcopter dengan penempatan empat motor yang memiliki jarak $40 \mathrm{~cm}$. Dan pada bagian atas sistem akan ditempatkan flight controller dan mikrokontroler. Sebagian besar bahan yang digunakan untuk kerangka quadcopter adalah aluminium, karena memiliki massa yang ringan (massa jenis: $2.70 \mathrm{gcm}^{-3}$ ) dan mudah didapat. Selain aluminium penulis juga menggunakan akrilik hitam dengan tebal $3 \mathrm{~mm}$ sebagai papan untuk menempatkan komponen.

2. Flight Controller KK Board v2.2

Sebagai pusat pemrosesan data dari receiver yang kemudian diteruskan ke motor melalui ESC.

3. Mikrokontroller ATMega328

Mikrokontroler bekerja pada level tegangan 5 volt. Semua port digital pin 0 sampai dengan 13 dan pin analog 0 sampai 5 bersifat bi-directional I/O dengan internal pull-up.

4. Sensor Inframerah Sharp GP2YOA21

Untuk mendeteksi adanya halangan digunakan sensor inframerah yang ditempatkan pada bagian depan, belakang, kiri, dan kanan dari kerangka sistem.
5. Kamera

Dalam proses pemantauan akan digunakan kamera dengan IP (Internet Protocol) yang diletakkan di bawah kerangka.

6. Receiver

Receiver yang digunakan adalah receiver sama dengan transmitter-nya, dengan tujuan agar komunikasi antara transmitter dan receiver tidak mengalami kendala atau error.

7. Landing Skid

Landing skid digunakan untuk mencegah terjadinya benturan langsung saat quadcopter melakukan pendaratan.

8. Motor BLDC dan Baling-Baling

Pemutar baling-baling yang digunakan sebagai penggerak quadcopter adalah motor BLDC (Brushless Direct Current) karena lebih efisien terhadap daya yang digunakan dan tidak membutuhkan perawatan.

9. Baterai

Digunakan sebagai sumber tegangan untuk mikrokontroler, flight controller, ESC dan motor agar dalam menjalankan sistem secara keseluruhan.

\section{Perancangan Perangkat Lunak}

Perangkat lunak dalam sistem ini menggunakan aplikasi sebagai pusat pemrograman yaitu menggunakan software IDE Arduino dengan bahasa pemrograman Arduino yaitu bahasa $C$ yang talah dipermudah dalam menggunakan fungsifungsi yang sederhana sehingga bisa dipelajari dengan mudah.

\section{Alur Sistem}

Proses awal dimulai dengan inisialisasi kalibrasi flight controller. Lalu mengecek keempat sensor inframerah apakah dalam keadaan ready. Kemudian dilakukan pengecekan terhadap penerimaan sinyal dari transmitter ke receiver pada quadcopter. Jika sinyal transmitter terdeteksi, maka quadcopter berada dalam kondisi armed, dan quadcopter siap untuk diterbangkan. Saat quadcopter terbang, dan sensor 1 mendeteksi halangan, maka quadcopter akan mundur dengan kondisi kecepatan 
M1, dan M2 lebih cepat dari M3 dan M4. Saat sensor 2 mendeteksi halangan, maka quadcopter akan melakukan roll ke kiri dengan kondisi kecepatan M1, dan M4 lebih cepat dari M2 dan M3.Saat sensor 3 mendeteksi halangan, maka quadcopter akan maju dengan kondisi kecepatan M1, dan M2 lebih rendah dari M3 dan M4. Saat sensor 2 mendeteksi halangan, maka quadcopter akan melakukan roll ke kanan dengan kondisi kecepatan M1, dan M4 lebih rendah dari M2 dan M3.

\section{Implementasi}

Adapun alur implementasi pembuatan quadcopter terlihat pada Gambar 4.

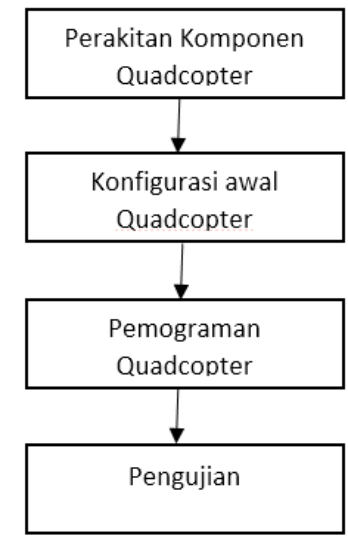

Gambar 4. Alur Implementasi

$$
\text { Langkah yang pertama yaitu }
$$
melakukan perakitan terhadap semua komponen hardware sehingga membentuk quadcopter. Pada tahap perakitan komponen quadcopter dengan sensor inframerah diperlukan beberapa bahan baku yaitu akrilik, alumunium, dan busa hati yang digunakan sebagai kerangka dari quadcopter.

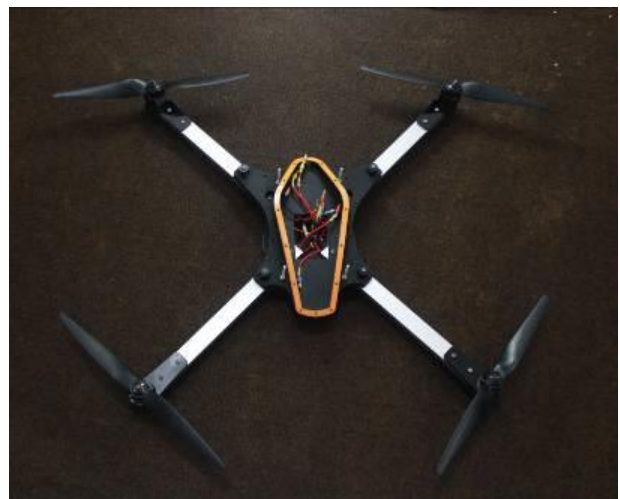

Gambar 5. Perakitan Quadcopter

Selanjutnya dilakukan konfigurasi awal. Konfigurasi awal pada quadcopter perlu dilakukan sebelum quadcopter dapat dioperasikan. Quadcopter dengan flight controller KK Board dapat dikonfigurasi langsung tanpa menggunakan perangkat komputer.

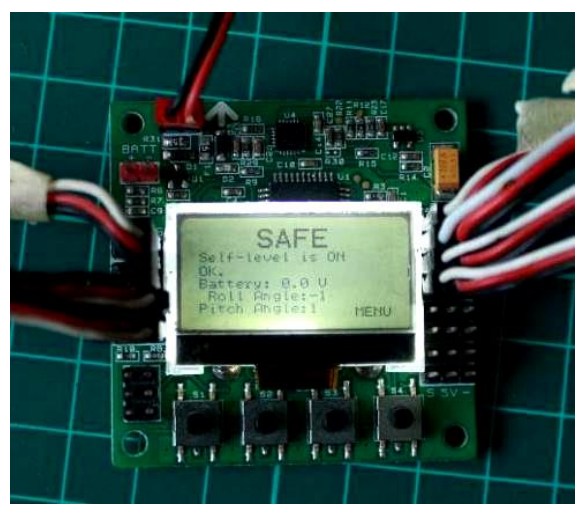

Gambar 6. Konfigurasi pada KK Board

Langkah $\begin{gathered}\text { selanjutnya } \\ \text { melakukan }\end{gathered}$ pemrograman
quadcopter. Pemrograman Arduino
menggunakan bahasa C. Terakhir yaitu
melakukan pengujian terhadap quadcopter.

\section{HASIL DAN PEMBAHASAN}

Dalam penelitian ini dilakukan dua pengujian diantaranya pengujian pembacaan jarak sensor inframerah dan pengujian keseluruhan sistem. Pengujian pertama dilakukan untuk mengetahui jarak pembacaan efektif dari sensor inframerah. Pengujian kedua adalah pengujian keseluruhan dilakukan untuk menguji apakah quadcopter yang dirancang mampu untuk memberikan gerakan feedback 
dengan jarak halangan diperoleh dari hasil pengujian pertama.

\section{Pengujian Sensor Inframerah}

Empat sensor inframerah dipasang di sebelah kanan, kiri, depan, dan belakang. Kemudian sebagai sarana pengujian, sebuah objek diletakkan pada jarak $20 \mathrm{~cm}, 40 \mathrm{~cm}, 60 \mathrm{~cm}, 80 \mathrm{~cm}, 100 \mathrm{~cm}$, $120 \mathrm{~cm}$, dan $140 \mathrm{~cm}$. Pada Tabel 1. dapat dilihat bahwa pengujian menunjukkan keempat sensor dapat bekerja dengan baik berdasarkan pada pendeteksian melalui indikator LED dan buzzer. Pada pengujian pertama dapat disimpulkan bahwa sensor inframerah dapat mengenali objek dengan baik pada jarak $20 \mathrm{~cm}$ sampai $80 \mathrm{~cm}$.

Tabel 1. Hasil Pengujian Sensor Inframerah

\begin{tabular}{|c|c|c|c|c|c|}
\hline $\begin{array}{c}\text { Sensor } \\
\text { ke- }\end{array}$ & $\begin{array}{c}\text { Pengujian } \\
\text { ke- }\end{array}$ & $\begin{array}{c}\text { Jarak Objek } \\
(\mathrm{cm})\end{array}$ & LED & Buzzer & Ket. \\
\hline \multirow{7}{*}{1} & 1 & 140 & OFF & OFF & T. Terdeteksi \\
\hline & 2 & 120 & OFF & OFF & T. Terdeteksi \\
\hline & 3 & 100 & OFF & OFF & T. Terdeteksi \\
\hline & 4 & 80 & OFF & OFF & T. Terdeteksi \\
\hline & 5 & 60 & ON & ON & Terdeteksi \\
\hline & 6 & 40 & ON & ON & Terdeteksi \\
\hline & 7 & 20 & ON & ON & Terdeteksi \\
\hline \multirow{7}{*}{2} & 1 & 140 & OFF & OFF & T. Terdeteksi \\
\hline & 2 & 120 & OFF & OFF & T. Terdeteksi \\
\hline & 3 & 100 & OFF & OFF & T. Terdeteksi \\
\hline & 4 & 80 & OFF & OFF & T. Terdeteksi \\
\hline & 5 & 60 & ON & ON & Terdeteksi \\
\hline & 6 & 40 & ON & ON & Terdeteksi \\
\hline & 7 & 20 & ON & ON & Terdeteksi \\
\hline \multirow{7}{*}{3} & 1 & 140 & OFF & OFF & T. Terdeteksi \\
\hline & 2 & 120 & OFF & OFF & T. Terdeteksi \\
\hline & 3 & 100 & OFF & OFF & T. Terdeteksi \\
\hline & 4 & 80 & OFF & OFF & T. Terdeteksi \\
\hline & 5 & 60 & ON & ON & Terdeteksi \\
\hline & 6 & 40 & ON & ON & Terdeteksi \\
\hline & 7 & 20 & ON & ON & Terdeteksi \\
\hline \multirow{7}{*}{4} & 1 & 140 & OFF & OFF & T. Terdeteksi \\
\hline & 2 & 120 & OFF & OFF & T. Terdeteksi \\
\hline & 3 & 100 & OFF & OFF & T. Terdeteksi \\
\hline & 4 & 80 & OFF & OFF & T. Terdeteksi \\
\hline & 5 & 60 & ON & ON & Terdeteksi \\
\hline & 6 & 40 & ON & ON & Terdeteksi \\
\hline & 7 & 20 & ON & ON & Terdeteksi \\
\hline
\end{tabular}

\section{Pengujian Keseluruhan}

Pengujian kedua yakni pengujian sistem secara keseluruhan. Pengujian dilakukan dengan meletakkan objek pada jarak $20-80 \mathrm{~cm}$ di depan keempat sensor inframerah secara bergantian. Jika objek terdeteksi pada range maka quadcopter akan bergerak ke arah berlawanan sesuai penjelasan pada bagian sebelumnya. Sebelumnya pengujian keseluruhan hanya dilakukan diluar ruangan untuk menguji sistem quadcopter pada kondisi real. Namun diperoleh hasil yang kurang memuaskan (akurasi dibawah 80\%) karena sensitifitas sensor inframerah yang mengalami penurunan karena dipengaruhi 
oleh cahaya matahari. Oleh karena itu dilakukan pula pengujian di dalam ruangan (tanpa cahaya matahari) sebagai pembanding untuk mengetahui performa dari sensor inframerah yang digunakan.

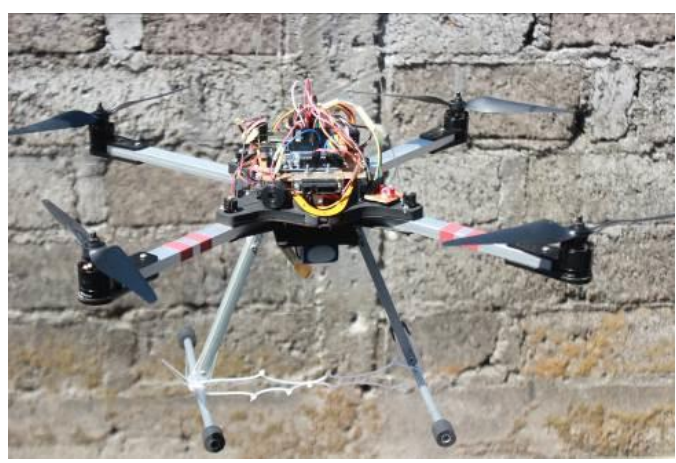

Gambar 6. Proses Pengujian Quadcopter di Luar Ruangan

\section{Pengujian di Luar Ruangan}

Pengujian ini bertujuan untuk mengimplementasikan cara kerja sensor inframerah yang digunakan untuk mendeteksi objek atau halangan. Pada pengujian ini, quadcopter digantung pada tiang horizontal, kemudian tuas throttle dinaikkan sehingga motor berputar. Pengujian dilakukan dengan mengamati respon sensor melalui indikator LED.

Tabel 2. Hasil Pengujian Sensor Depan di Luar Ruangan

\begin{tabular}{|c|c|c|c|c|c|c|c|c|c|}
\hline \multirow{3}{*}{$\begin{array}{c}\text { Pengujian } \\
\text { ke - }\end{array}$} & \multicolumn{8}{|c|}{ Respon LED } & \multirow{3}{*}{$\begin{array}{c}\text { Ket. Respon } \\
\text { Mundur }\end{array}$} \\
\hline & \multicolumn{2}{|c|}{ Depan } & \multicolumn{2}{|c|}{ Kanan } & \multicolumn{2}{|c|}{ Belakang } & \multicolumn{2}{|c|}{ Kiri } & \\
\hline & $\mathrm{NH}$ & NU & $\mathrm{NH}$ & NU & $\mathrm{NH}$ & NU & $\mathrm{NH}$ & $\mathrm{NU}$ & \\
\hline 1 & $Y$ & $Y$ & $N$ & $\mathrm{~N}$ & $N$ & $Y$ & $\mathrm{~N}$ & $N$ & $Y$ \\
\hline 2 & $Y$ & $Y$ & $\mathrm{~N}$ & $\mathrm{~N}$ & $\mathrm{~N}$ & Y & $\mathrm{N}$ & $Y$ & Y \\
\hline 3 & $Y$ & Y & $\mathrm{N}$ & $\mathrm{N}$ & $\mathrm{N}$ & Y & $\mathrm{N}$ & $Y$ & Y \\
\hline 4 & $Y$ & Y & $\mathrm{N}$ & $\mathrm{N}$ & $\mathrm{N}$ & Y & $\mathrm{N}$ & $\mathrm{N}$ & Y \\
\hline 5 & $Y$ & $Y$ & $\mathrm{~N}$ & $\mathrm{~N}$ & $\mathrm{~N}$ & $Y$ & $\mathrm{~N}$ & $\mathrm{~N}$ & Y \\
\hline
\end{tabular}

Keterangan:

$\mathrm{NH}$ : Nilai Harapan

$\mathrm{NU}$ : Nilai Uji

Y: Yes (ya)

$\mathrm{N}$ : No (tidak)

Persentase akurasi $=$ jumlah nilai sesuai/jumlah uji x $100 \%$

Persentase akurasi sensor = Jumlah persentase akurasi/ jumlah pengujian

Di luar ruangan telah dilakukan pengujian terhadap keempat sensor yang berada pada kanan, kiri, depan, dan belakang quadcopter. didapat hasil bahwa sensor telah berhasil mendeteksi adanya objek, namun terjadi beberapa kesalahan deteksi pada sensor lain. Nilai akurasi masing-masing sensor yaitu sensor depan (65\%), sensor kanan (65\%), sensor belakang $(60 \%)$, serta sensor kiri $(50 \%)$. Akurasi sensor secara keseluruhan adalah $61,25 \%$. Kesalahan deteksi sensor disebabkan oleh lingkungan di luar ruangan yang terang sehingga mengganggu pendeteksian sensor.

\section{Pengujian di Dalam Ruangan}

Pengujian ini dilakukan sebagai nilai pembanding dari pengujian sebelumnya. Pengujian ini dilakukan di dalam ruangan tertutup dengan digantung dengan tiang horizontal.

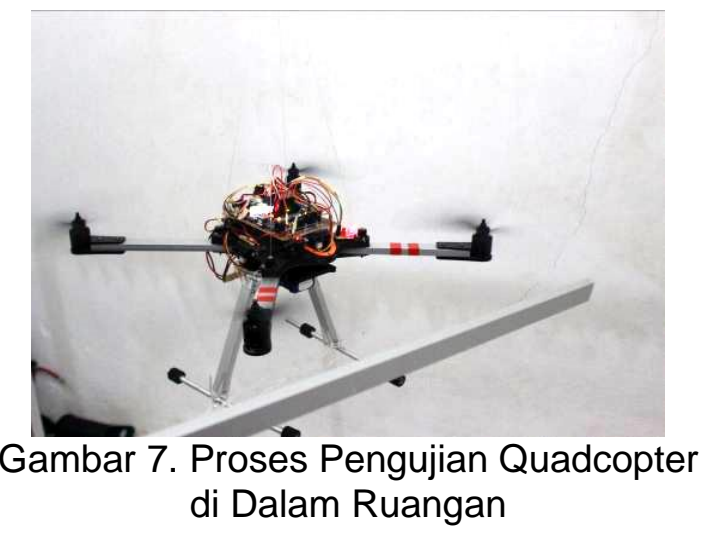


Tabel 3. Hasil Pengujian Sensor Depan di Dalam Ruangan

\begin{tabular}{|c|c|c|c|c|c|c|c|c|c|}
\hline \multirow{3}{*}{$\begin{array}{c}\text { Pengujian } \\
\text { ke - }\end{array}$} & \multicolumn{8}{|c|}{ Respon LED } & \multirow{3}{*}{$\begin{array}{c}\text { Ket. } \\
\text { Respon } \\
\text { Kanan }\end{array}$} \\
\hline & \multicolumn{2}{|c|}{ Depan } & \multicolumn{2}{|c|}{ Kanan } & \multicolumn{2}{|c|}{ Belakang } & \multicolumn{2}{|c|}{ Depan } & \\
\hline & $\mathrm{NH}$ & $\mathrm{NU}$ & & $\mathrm{NH}$ & NU & & $\mathrm{NH}$ & $\mathrm{NU}$ & \\
\hline 1 & $\mathrm{Y}$ & $\mathrm{Y}$ & 1 & $\mathrm{Y}$ & $\mathrm{Y}$ & 1 & $\mathrm{Y}$ & $\mathrm{Y}$ & 1 \\
\hline 2 & $Y$ & Y & 2 & Y & $Y$ & 2 & $Y$ & $Y$ & 2 \\
\hline 3 & Y & Y & 3 & Y & Y & 3 & $Y$ & $Y$ & 3 \\
\hline 4 & Y & $Y$ & 4 & Y & Y & 4 & $Y$ & $Y$ & 4 \\
\hline 5 & Y & $Y$ & 5 & $Y$ & $Y$ & 5 & $Y$ & $Y$ & 5 \\
\hline
\end{tabular}

Dalam hasil pengujian, dapat dilihat bahwa sensor dapat mendeteksi dan merespon adanya objek dengan tingkat akurasi $100 \%$. Masing-masing sensor dapat mendeteksi objek tanpa adanya kesalahan deteksi.

\section{SIMPULAN DAN SARAN}

Berdasarkan pada hasil penelitian yang telah dilakukan dapat disimpulkan sebagai berikut, yaitu:

1. Perancangan quadcopter obstacle avoidance ini terdiri dari beberapa tahap, yaitu perancangan kerangka quadcopter, perakitan komponen elektronika, konfigurasi flight controller, pemrograman dengan bahasa $C$ Arduino yang di-upload ke mikrokontroler.

2. Pengujian sensor inframerah dengan jarak antara objek dan sistem dari 20 $\mathrm{cm}$ sampai $80 \mathrm{~cm}$ hasilnya objek terdeteksi, sedangkan pada jarak 100 $\mathrm{cm}$ sampai $140 \mathrm{~cm}$, sensor tidak mendeteksi adanya objek.

3. Pengujian quadcopter obstacle avoidance hasilnya pada saat diuji di luar ruangan, terjadi kesalahan deteksi sehingga menurunkan akurasi sensor menjadi $61.25 \%$. Sedangkan pada saat diuji di dalam ruangan tertutup, quadcopter dapat merespon objek dengan tingkat akurasi $100 \%$.

Adapun beberapa saran yang diusulkan untuk pengembangan selanjutnya yaitu:

1. Menambah sensor ultrasonik yang difungsikan untuk menjaga ketinggian (altitude hold) sehingga quadcopter menjadi lebih stabil dan pendeteksian halangan menjadi lebih akurat.

2. Menghitung waktu respon yang dibutuhkan sensor inframerah atau ultrasonik yang digunakan dalam mendeteksi halangan yang diberikan.

3. Menambahkan kasus pengujian lebih dari satu objek halangan disaat yang sama sehingga menghasilkan pergerakan quadcopter yang lebih dinamis.

\section{DAFTAR RUJUKAN}

Badan Nasional Penanggulangan Bencana. 2017. Undang-Undang Republik Indonesia Nomor 24 Tahun 2007 tentang Penanggulangan Bencana.

https://bnpb.go.id/ppid/file/UU 2420 07.pdf (diakses: 17 Januari 2018)

Burhany, A. 2014. Antisipasi Bencana Alam Dengan Memfasilitasi Sarana Pengetahuan di Indonesia. Jurnal Tingkat Sarjana Senirupa dan Desain ITB no.1 hlm 1-8.

Ekayana, G. 2016. Rancang Bangun Alat Pengering Rumput Laut Berbasis Mikrokontroler Arduino Uno. Jurnal Pendidikan Teknologi dan Kejuruan Universitas Pendidikan Ganesha, Vol 13, No. 1

Fatoni, A. 2015. Rancang Bangun Alat Pembelajaran Microcontroller Berbasis ATMega 328 di Universitas 
Serang Raya. Jurnal PROSISKO vol. 2 No. $1 \mathrm{hlm}$. 10-18.

Latif, M. 2014. Perancangan Sistem Autonomous Quadcopter. Seminar Nasional Sains dan Teknologi Fakultas Teknik Universitas Muhammadiyah. hlm. 1-5.

Lubis, A. 2017. Rancang Bangun Model Quadcopter Dengan Control PID (Proportional Integral Derivative) Sebagai Kendali Gerakan Hover Pada UAV (Unmanned Aerial Vehicle) Quadcopter. JITEKH vol. 6 no. 02 hlm. 77-82.
Nataliana, D. 2014. Sistem Monitoring Parkir Mobil Menggunakan Sensor Infrared Berbasis Raspberry Pi. Jurnal ELKOMIKA no. 1 vol. $2 \mathrm{hlm}$. 68-84.

Silvia, A. 2014. Rancang Bangun Akses Kontrol Pintu Gerbang Berbasis Arduino dan Android. ELECTRANS vol. 13 no. $1 \mathrm{hlm}$. 1-10.

Swamardika, A. dkk. 2014. Rancang Bangun Quadcopter Robot Sebagai Alat Pemantau Jarak Jauh Kawasan Lingkungan Bencana. Seminar Nasional Sains dan Teknologi. Universitas Udayana 